\title{
Getting rid of rain and stars: mitigating inhibition effects in ddPCR assays, the case of the invasive crayfish Pacifastacus leniusculus in the streams of Luxembourg
}

\author{
David Porco ${ }^{\ddagger}$, Sylvie Hermant ${ }^{\ddagger}$, Chanistya Ayu Purnomo ${ }^{\ddagger}$, Mario Horn ${ }^{\ddagger}$, Guy Marson${ }^{\ddagger}$, Guy Colling ${ }^{\ddagger}$
}

‡ Musée national d'histoire naturelle, Luxembourg, Luxembourg

Corresponding author: David Porco (david.porco.gm@gmail.com)

Received: 25 Feb 2021 | Published: 04 Mar 2021

Citation: Porco D, Hermant S, Purnomo CA, Horn M, Marson G, Colling G (2021) Getting rid of rain and stars: mitigating inhibition effects in ddPCR assays, the case of the invasive crayfish Pacifastacus leniusculus in the streams of Luxembourg. ARPHA Conference Abstracts 4: e65045. https://doi.org/10.3897/aca.4.e65045

\begin{abstract}
ddPCR is getting more and more popular in the field of eDNA-based aquatic monitoring. Even if emulsion PCR used in ddPCR confers a partial resistance to inhibition due to the high number of reactions for the same sample (between $10 \mathrm{~K}$ and $20 \mathrm{~K}$ ), it is not impervious to it. Inhibition impacts the fluorescence amplitude of positive droplets, affecting both their dispersion and their position relatively to the negative droplets cloud. This fluctuation could jeopardize the use of a shared threshold among several samples and thus the objective assignation of the positive droplets.

This is even more critical for low concentration samples such as eDNA samples: the positive droplets are scarce and it is thus crucial to objectively discriminate if they can be counted as positive by establishing an appropriate threshold. Another issue is the artifactual generation of high fluorescence droplets that could be counted as positive with a single threshold solution.

Here we propose a double threshold method to take both high fluorescence droplets and PCR inhibition impact into account allowing for an objective sorting of the positive and negative droplets in ddPCR assays.
\end{abstract}




\section{Keywords}

ddPCR, inhibition, data treatment, crayfish, Pacifastacus leniusculus, streams, eDNA, invasive species

\section{Presenting author}

David Porco

\section{Presented at}

1st DNAQUA International Conference (March 9-11, 2021) 